\title{
Discussion on Dynamic Numerical Simulation for Earthquake of Immer- sed Tunnel at Seabed
}

\author{
Yang Bo ${ }^{1, *}$, Zheng Yingren ${ }^{1,2}$ and Li Xiud ${ }^{1}$ \\ ${ }^{1}$ Department of Civil Engineering, Logistical Engineering University, Chongqing 401311, China; ${ }^{2}$ Chongqing Key \\ Laboratory of Geomechanics \& Geoenvironment Protection, Chongqing 400041, China
}

\begin{abstract}
The finite element limit analysis method is applied to study the reinforcement concrete immersed tunnel at seabed under earthquake in this paper. FLAC3D is adopted to establish the equivalent model of reinforcement concrete, and the solution is executed according to elastic-plastic plane problem. Firstly, it is indicated that there are extreme strain values for concrete and reinforcement concrete, and the finite element limit method is adopted to calculate the ultimate shear strain value of equivalent material test pieces of reinforcement concrete of immersed tunnel so as to judge whether the immersed tube failures, thus, a new failure criteria for finite element limit analysis of immersed tunnel is provided. Secondly, the location and shape of failure surface of the immersed tunnel are simulated and its safety factor is obtained, and relation curve between subsidence displacement of top plate and strength reduction factors is combined to analyze the whole failure process of immersed tube. Finally, the influence law for safety factors of immersed tunnel under the function of different seismic wave.
\end{abstract}

Keywords: Failure criterion, finite element limit method, immersed tunnel at seabed, safety factor, seismic wave, ultimate shear strain, whole failure process.

\section{INTRODUCTION}

The subsea tunnel not only drives the sustainable highspeed development of coastal economy and ocean development in our country but also has such characteristics as no obstruction for airline and no influence on ecological environment. Within recent years, the projects that have already been completed and will be developed continuously in China cover subsea tunnel in Xiamen, subsea tunnel in Qingdao, subsea tunnel in Hong Kong, Zhuhai and Macau and Chongming Tunnel in Shanghai, these major sea-spanning transportation facilities with huge investment have huge function on nationwide and regional national economy as well as social development. Based on incomplete statistics, there are over hundreds of constructed sea-spanning tunnels and channel traffic tunnels within recent hundreds of years.

Currently, the study method used for dynamic stability analysis on earthquake for subsea tunnel mainly covers the quasi-static method, reaction displacement and finite element method [1-3]. The computation of quasi-static method and reaction displacement method are simple relatively, however, the precision is worse. The finite element method can accurately treat the complex underground project problems.

The purpose of this paper is to apply the finite element limit analysis method $[4,5]$ and finite difference software $[6$, 7] as well as firstly put forward the ultimat shear strain value of reinforcement concrete materials to serve as the new failure criterion of finite element limit analysis method. Secondly, the location and shape of failure surface for this immersed tunnel are simulated and the safety factor is obtained.

\section{INTRODUCTION TO FINITE ELEMENT STRENGTH REDUCTION METHOD FOR IM- MERSED TUNNEL}

The authors have completed the stability analysis on finite element strength reduction for reinforced concrete immersed tunnel at seabed under static force condition; following basic conclusions can be used for stability analysis on earthquake dynamic for immersed tunnel.

\subsection{Grid Division}

The frequency component of input waveform and wave velocity characteristic of soil mass may influence the numerical precision of diffusion. Kuhlemeyer and Lysmer (1973)'study shows that, if the wave propagation in the model is desired to be described accurately, the grid dimension $\mathrm{L}$ must be less than $1 / 8 \sim 1 / 10$ wavelength corresponding to maximal frequency of waveform. The grid division shall be conducted according to the requirement in this paper.

\subsection{Equivalent Strength and Reduction Method of Rein- forcement Concrete Immersed Tube}

The reinforcement concrete equivalent model is adopted in this paper to compute the dynamic response of reinforcement concrete immersed tunnel at the seabed. The model is divided into such two types as equivalent unit combined by reinforcement and concrete and plain concrete unit. It is assumed that the shearing force undertaken by equivalent materials equals to the sum of bearing force undertaken by con- 
crete and reinforcement. Based on the compatibility principle of reinforcement and concrete deformation, the shearing strength index $c, \tan \varphi$ and tensile strength $\sigma$ of reinforced concrete equivalent materials may be obtained. While analyzing the strength reduction method, remain the parameter of soil layer invariable, only the obtained equivalent parameters of reinforced concrete and equivalent parameters of plain concrete are reduced until destroyed. The strength reduction factor at this moment is defined as safety factor of immersed tunnel.

The equivalent strength parameters of reinforced concrete are inferred as follows:

Shearing force $s$ borne by reinforced concrete equivalent materials equals to sum shearing force $S_{c}$ borne by concrete and shearing force $s_{s}$ borne by reinforcement.

$s=s_{c}+s_{s}$

When the concrete reaches the shearing failure firstly, the shearing force of equivalent material is:

$s=(c+\sigma \tan \varphi) \cdot A$

In Formula, $c$ and $\varphi$ refer to shearing strength indexes of equivalent material respectively ; $\sigma$ is normal stress on the shearing surface ; $A$ is shearing area.

Right now, the concrete is in limit equilibrium status, and the borne shearing stress and shearing force are as follows respectively:

$\tau_{c}=c_{c}+\sigma \tan \varphi_{c}$

$S_{c}=\left(c_{c}+\sigma \tan \varphi_{c}\right) \cdot A_{c}$

In Formula, $c_{c}$ and $\varphi_{c}$ refer to shearing strength indexes of concrete respectively ; $A_{c}$ refers to shearing area of concrete.

It is assumed that the deformation of reinforcement and concrete coordinate, and the shearing strain of reinforcement and concrete is equal. Based on the definition of shearing strain, the shearing strain is:

$\gamma_{c}=\frac{\tau_{c}}{G_{c}}=\frac{c_{c}+\sigma \tan \varphi_{c}}{G_{c}}$

In Formula, $G_{c}$ is shear modulus of concrete.

The shearing force borne by reinforcement is:

$s_{s}=\gamma_{s} \cdot G_{s} \cdot A_{s}=\gamma_{c} \cdot G_{s} \cdot A_{s}$

$=\frac{c_{c}+\sigma \tan \varphi_{c}}{G_{c}} \cdot G_{s} \cdot A_{s}$

In Formula, $G_{s}$ is shear modulus of reinforcement.

Therefore, obtain from $s=s_{c}+s_{s}$

$(c+\sigma \tan \varphi) \cdot A$

$=\left(c_{c}+\sigma \tan \varphi_{c}\right) A_{c}+\frac{c_{c}+\sigma \tan \varphi_{c}}{G_{c}} \cdot G_{s} \cdot A_{s}$
Clear up above formula and respectively obtain the shearing strength indexes of reinforcement concrete equivalent material:

$c=\left[1+\left(\frac{G_{s}}{G_{c}}-1\right) \cdot v_{s}\right] \cdot c_{c}$

$\tan \varphi=\left[1+\left(\frac{G_{s}}{G_{c}}-1\right) \cdot v_{s}\right] \cdot \tan \varphi_{c}$

In Formula, $v_{s}$ is reinforcement ratio of reinforced concrete.

After the tensile yield of concrete, the tensile stress of reinforced concrete material is borne by the reinforcement fully, the tensile strength of equivalent unit is achieved via above similar deduction.

\section{SELECTION FOR FINITE ELEMENT MODEL AND GEOTECHNICAL PARAMETERS}

\subsection{Numerical Model}

The immersed tunnel is composed by two highway passageways and an auxiliary passageway in the middle. The total width of tunnel is about $38 \mathrm{~m}$ and the total height is $11.5 \mathrm{~m}$, with $1.5 \mathrm{~m}$ thick top plate, $1.5 \mathrm{~m}$ thick bottom plate, $0.8 \mathrm{~m}$ thick medium wall and $0.8 \mathrm{~m}$ thick side wall. The castin-situ concrete strength grade is C50.

On the computed sectional soil layer, there are sludge (3.0m in thickness), backfilling materials $(11.5 \mathrm{~m}$ in thickness) and dense coarse sand $(40.0 \mathrm{~m}$ in thickness). The distance between seawater surface and seabed is $10 \mathrm{~m}$. The calculation scope in horizontal direction is $206 \mathrm{~m}$.

The finite difference software flac3d is adopted to conduct the numerical simulation. Eight-node and hexahedron entity unit is adopted for immersed tube and soil mass. In order to enable that the mechanical behavior of equivalent material further conforms to the reinforcement distribution characteristics of actual immersed tube. On the basis of analyzing the influence on influence discipline for computation results by unit dimension magnitude, $\mathrm{z}$ direction of top plate for immersed tube is divided into 6-layer units, therefore, two-layer units on the top and bottom are of reinforcement concrete equivalent units, four-layer units in the middle are of plain concrete units. While modeling, the actual immersed tube is simplified locally. The geometry and stress symmetry of immersed tube are employed, the established numerical model and grid division of immersed tube unit are as shown in Fig. (1).

\subsection{Computation Parameters}

The elastoplastic constitution relation is adopted for model, namely, Mohr-Coulomb Strength Code. The dry density is given in the Table $\mathbf{1}$, and the humidity saturation property is completed via automatic computation by fluid model. The physical and mechanical parameters of materials adopted in this computation are as shown in Table $\mathbf{1}$. 


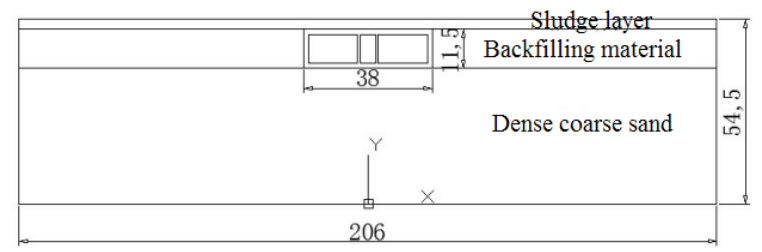

(a) Numerical Calculation Model Diagram

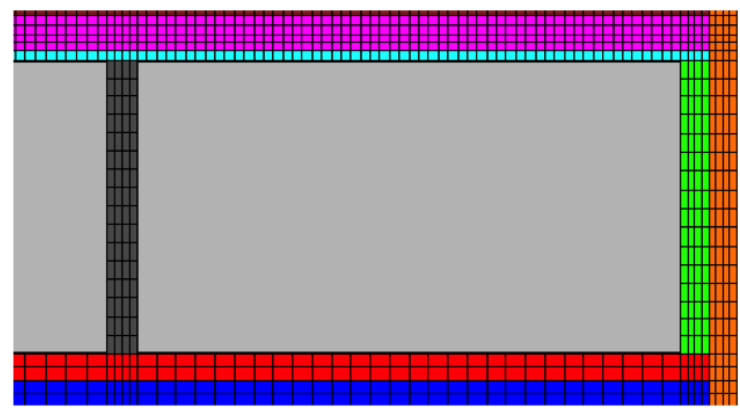

(b) Division for Immersed Tube Unit

Fig. (1). Numerical calculation model of immersed tunnel.

Table 1. Physical and mechanical parameters of materials.

\begin{tabular}{|c|c|c|c|c|c|c|}
\hline Material Name & $\begin{array}{r}\text { Density } \\
\left(\mathrm{kg} / \mathbf{m}^{3}\right)\end{array}$ & $\begin{array}{c}\text { Elasticity } \\
\text { Modulus } \\
\text { (MPa) }\end{array}$ & $\begin{array}{c}\text { Poisson's } \\
\text { ratio }\end{array}$ & $\begin{array}{c}\text { Cohesion } \\
\text { (kPa) }\end{array}$ & $\begin{array}{c}\text { Inner fric- } \\
\text { tional angle } \\
\left(^{\circ}\right)\end{array}$ & $\begin{array}{c}\text { Tensile } \\
\text { strength } \\
\text { (kPa) }\end{array}$ \\
\hline Silt at seabed & 1250 & 20 & 0.33 & 0 & 30 & 0 \\
\hline Clay & 1350 & 50 & 0.33 & 30 & 20 & 10 \\
\hline C50 concrete & 2600 & 34500 & 0.2 & 5000 & 58 & 1830 \\
\hline Reinforcement & 7850 & 200000 & 0.2 & 210000 & 0 & 360000 \\
\hline
\end{tabular}

The contact surface unit is set between immersed tube and soil layer to be used for simulating the faulting, slippage, separation and closure between immersed tube and soil layer. "Moving Around" method is adopted for modeling of contact surface, and the contact surface is non-permeate boundary. The maximal dimension for taken contact surface unit is $0.4 \mathrm{~m}$, the normal rigidity and tangential rigidity are of $100 \mathrm{MPa} / \mathrm{m}$ uniformly, with $0 \mathrm{MPa}$ for cohesive force and $5^{\circ}$ for internal frictional angle. The local impedance with 0.157 for impedance coefficient is adopted for computation.

\subsection{Boundary Condition}

The model bottom is fixed, manual boundary on both sides is restricted horizontally, and the top surface of sludge layer is free boundary. The seawater pressure is served as the external loading to be imposed on the top surface of covered sludge layer on the immersed tube. The seawater pressure is determined via calculation. Therein, $\rho$ is water density, $g$ is gravitational acceleration, $h$ is seawater depth。The nonseepage mode is adopted to simulate the influence of sweater pressure in the soil. According to seawater depth, the initial pore pressure is set in the soil; the seawater pore pressure in the immersed tube is fixed as zero. While computing the numerical power, the seismic acceleration waveform is imposed directly on the bottom surface of model, and the boundary conditions of free field are adopted around model. The side boundary of main grid couples the grid of free field via damper. The schematic diagram of boundary conditions is as shown in Fig. (2).

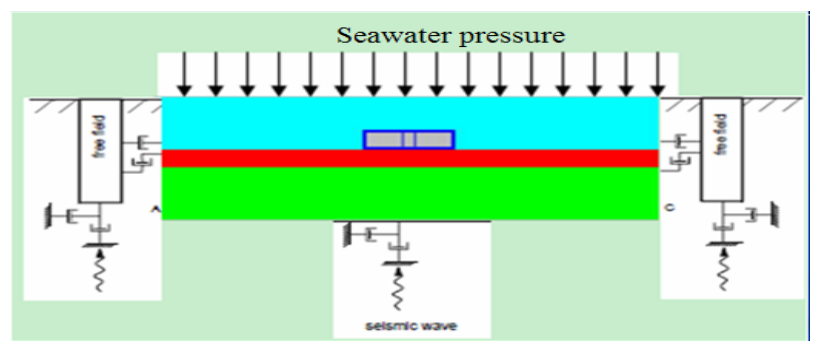

Fig. (2). Schematic diagram of boundary conditions for immersed tube.

\subsection{Seismic Wave Input}

One-way horizontal input along reinforced concrete immersed tunnel at the seabed is adopted for computation in 
this paper, with adoption of multiple waveform input. $0.22 \mathrm{~g}$ and $0.2 \mathrm{~g}$ are taken respectively for earthquake peak acceleration, with $10 \mathrm{~s}$ and $7 \mathrm{~s}$ for time respectively. The seismic wave computed and input in this paper is adjusted according to requirement, and the filtering and baseline correction are conducted. Four kinds of seismic wave proposed to be adopted in this paper respectively cover: duration of (1) wave is $7 \mathrm{~s}$ and the earthquake peak acceleration is $0.2 \mathrm{~g}$, referring to Wave A for short; duration of (2) wave is $10 \mathrm{~s}$ and the earthquake peak acceleration is $0.2 \mathrm{~g}$, referring to Wave $\mathrm{B}$ for short; duration of (3) wave is $10 \mathrm{~s}$ and the earthquake peak acceleration is $0.22 \mathrm{~g}$, referring to Wave $\mathrm{C}$ for short; duration of (4) wave is $7 \mathrm{~s}$ and the earthquake peak acceleration is $0.2 \mathrm{~g}$, referring to Wave $\mathrm{C}$ for short. Relation of various seismic waves: A seismic wave is obtained by B seismic wave compression; the acceleration time travel curve for three kinds of A, B and C seismic wave is similar and is different from acceleration time travel curve of $\mathrm{D}$ seismic wave. The acceleration time travel curve of A, B, C and D seismic wave is as shown in Fig. (3).

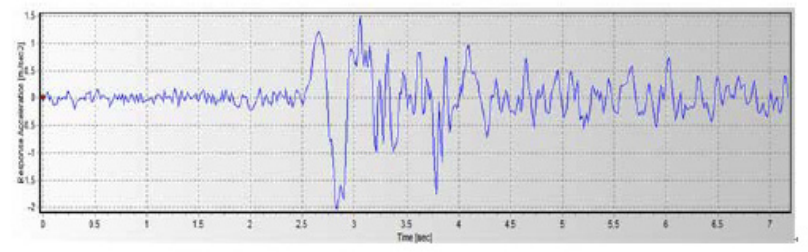

(a) Wave $\mathrm{A}$ ( $7 \mathrm{~s}$ for duration, $0.2 \mathrm{~g}$ for maximal acceleration )

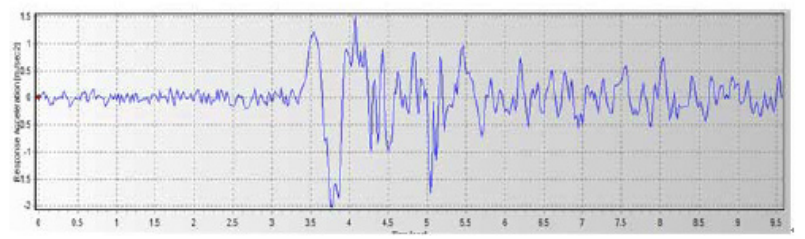

(b) Wave B (10s for duration, $0.2 \mathrm{~g}$ for maximal acceleration)

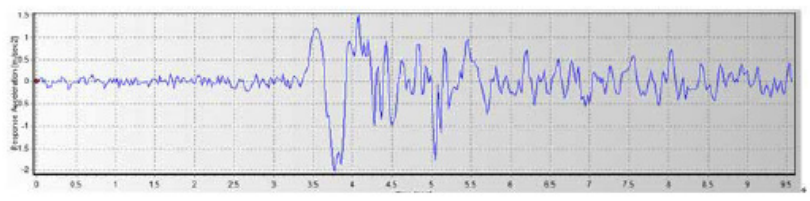

(c) Wave $\mathrm{C}(10 \mathrm{~s}$ for duration, $0.22 \mathrm{~g}$ for maximal acceleration)

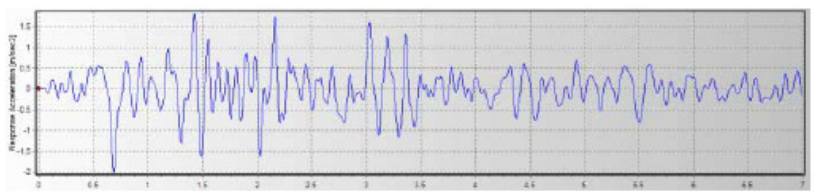

(d) Wave $\mathrm{D}(0.2 \mathrm{~g} 7 \mathrm{~s}$ for duration, $0.2 \mathrm{~g}$ for maximal acceleration)

Fig. (3). Acceleration time interval diagram of earthquake wave peak acceleration.

\section{DETERMINATION ON LIMIT SHEARING STRAIN OF EQUIVALENT MATERIALS}

\subsection{Presentation for Failure Criteria of Limit Shearing Strain}

In the geotechnical engineering, following three criterias are adopted for finite element limit analysis method to judge whether the geotechnical engineering is destroyed [8-10], firstly, whether the tensile failure area and shearing plasticity area are of cut through; secondly, in the computation, whether the force and displacement converge; thirdly, whether the displacement of potential sliding surface mutates. When the reinforced concrete structure bears the dynamic function of earthquake, except for above-said criteria, the rest criteria is difficult to be applicable, therefore, it is necessary to find a another new way.

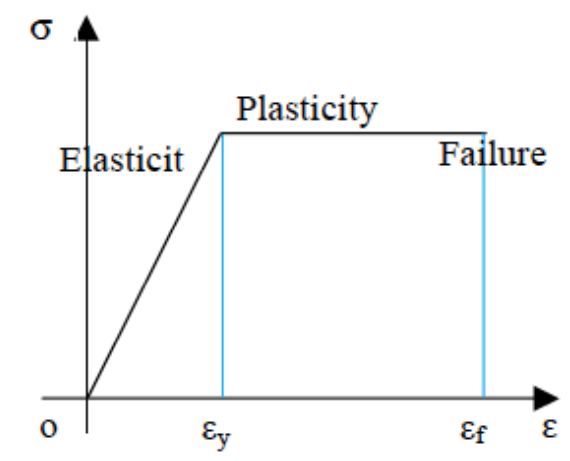

Fig. (4). Ideal elastic- plastic stress - strain curve.

Currently, there still isn't an apparent criterion to judge the integral failure of material; however, integral failure criterion of material may be adopted in the limit analysis to judge whether the materials are destroyed. In Fig. (4), if the ideal plastic stress strain curve is expressed by the stress, it is shown that the stress is invariable and the strain increase infinitely. Right now, the yielding criterion is consistent with failure criterion and is difficult to judge whether to be destroyed. However, if the presentation is executed by strain, the criterion of just reaching the yield is initial yield of material and is provided with elasticity limit strain $\varepsilon_{y}$, and the materials can't be destroyed; however, when the strain reaches the failure, it is provided with plasticity limit strain $\varepsilon_{\mathrm{f}, \text { and }}$ the materials are destroyed. It is visible that there is a limit shearing strain value for concrete failure. When the shearing strain of each point on the material failure surface is greater than the limit shearing strain uniformly, it is deemed that the integral failure of materials has been produced, thus, this may be served as the criterion of integral failure for materials. The limit shearing strain value is relevant to material strength and deformation nature, however, the property of concrete with different strength grades is invariable, therefore, $\mathrm{s}$ corresponding shearing strain limit value may be obtained.

In FLAC software, the shearing strain is expressed in increment form, the given shearing strain refers to accumulated shearing strain increment value, and the limit shearing strain increment refers to the limit shearing strain. Therefore, the failure that FLAC number is employed to simulate the reinforced concrete immersed tube shows that the minimal strain increment value on the failure surface of immersed tube is greater than limit strain increment value.

The immersed tube model is composed by concrete unit and reinforced concrete equivalent unit, therein; the one that plays a decisive role is reinforced concrete equivalent unit, what's more, the reinforced concrete equivalent unit locates at the top and bottom of beam, with larger deformation, therefore, we only require studying the reinforced concrete 
equivalent unit's failure, the failure of immersed tube may be reflected.

\subsection{Computation on Limit Shearing Strain Increment}

Determination method for limit shearing strain increment value during limit equilibrium: Through giving such parameters as cohesion force $c$, internal frictional angle $\phi$, transubstantiation modulus $\mathrm{K}$ and shearing modulus of equivalent concrete material for cube test piece with $150 \mathrm{~mm}$ in slide length in FLAC, the over-loading method in the finite element limit analysis method is applied to ensure that the model reaches the limit equilibrium stat, right now, the limit loading value and limit shearing strain increment value when the model is to be destroyed may be obtained; if the loading increases slightly, the shearing strain increment mutates. The computation model and result are as shown in Fig. (5), (6) and Table 2, and the obtained limit shearing strain increment value of immersed tube is $0.94 \times 10^{-3} \sim 1 \times 10^{-3}$ and is served as the failure criterion. We have ever performed the experiment for $\mathrm{C} 25$ concrete test piece; both failure surfaces computed via actual measurement for failure of test piece and in accordance with limit shearing strain are consistent so as to demonstrate the correctness of criterion. For this computation example, the failure judgment basis for reinforced concrete immersed tube is: when the shearing strain increment of each point on the failure surface of reinforced concrete immersed tube is greater than limit strain increment value $1 \times 10^{-3}$, the immersed tube is destroyed. We will mention later that, the immersed tube failure defined herein is immersed tube's fissure cut through actually.

It should be indicated that the frictional force isn't considered normally for concrete structure, this is because the confining pressure of concrete components is tiny and the frictional force isn't great. While considering the frictional force, the limit bearing force and limit strain value when there is confining pressure for test piece increase than the ones while performing the uniaxial test, however, when the confining pressure isn't great, the increment value isn't great. Table 2 shows the limit strain value when the confining pressure of $\mathrm{C} 25$ concrete and equivalent reinforcement concrete is 0 and $1 \mathrm{MPa}$, the difference for both of them isn't great. The confining pressure for soil mass of immersed tunnel is farther less than $1 \mathrm{MPa}$, Therefore; the limit strain value according to uniaxial test may be served as the computation standard.

Table 2. Scope of limit strain minimum.

\begin{tabular}{|c|c|c|}
\hline \multirow{2}{*}{ Model } & $\begin{array}{c}\text { Confining pressure } \\
\text { of test piece(MPa) }\end{array}$ & $\begin{array}{c}\text { Scope of limit shearing } \\
\text { strain increment mini- } \\
\text { mum (\%) }\end{array}$ \\
\hline \hline \multirow{2}{*}{ C25 } & 0 & $0.94-0.96$ \\
\cline { 2 - 3 } & 1 & $0.96-1.0$ \\
\hline \multirow{2}{*}{$\begin{array}{c}\text { Equivalent rein- } \\
\text { forced concrete }\end{array}$} & 0 & $0.94-1.00$ \\
\cline { 2 - 3 } & 1 & \\
\hline
\end{tabular}

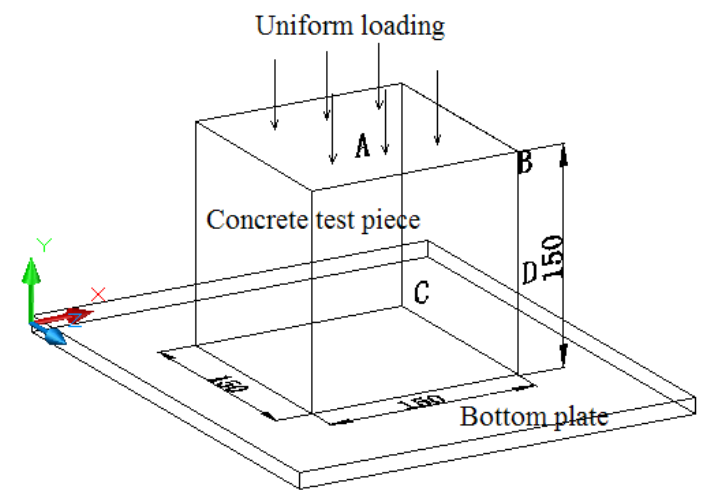

Fig. (5). Computation model.

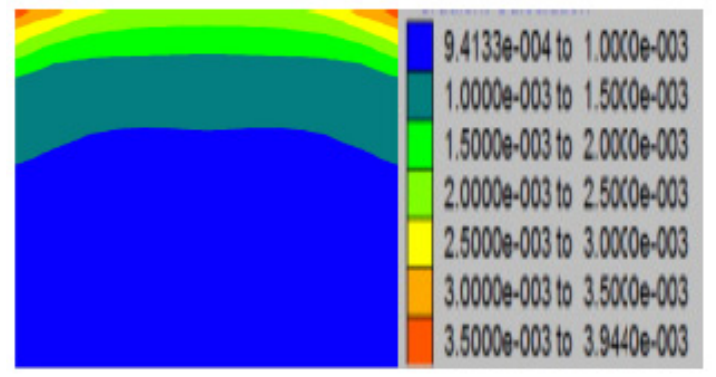

Fig. (6). Shearing strain increment diagram while limit equilibrium of cube test piece.

\section{ANALYSIS ON SIMULATION RESULTS}

\subsection{Judgment on Immersed Tube Failure}

\subsubsection{Determination for Failure Location of Immersed Tube}

After the numerical simulation ends, when the strength reduction factor is 2.0 respectively, the shearing strain increment of immersed tube refers to Fig. (7) respectively. It may be observed from Fig. (7) (a) that the location with greater shearing strain increment locates inside the top plate, in the middle of top plate and outside the top plate (two channels on the left and right are identical completely, take right channel as example). It may be observed from Fig. (7) (b), (c) and (d) that, when the reduction factor is 2.0, the minimum of shearing strain outside the top plate is $0.8 \times 10^{-3}$, the minimum of shearing strain in the top plate is $0.4 \times 10^{-3}$, and the minimum of shearing strain inside the top plate is $0.45 \times 10^{-3}$,therefore, the preferential failure location of immersed tube locates outside the top plate in the channel.

\subsubsection{Distinguishing on Instability for Immersed Tube by Limit Strain Increment}

With increase of reduction factor, the shearing strain increment of immersed tube increases continuously. When the shearing strain increment for certain cross section of immersed tube exceeds the shearing strain increment while limit equilibrium, we deem that the immersed tube fails, the reduction factor at this moment is defined as the safety factor of immersed tube. In fact, the immersed tube produces the fissure cutthrough here. The computed limit shearing strain increment of immersed tube computed previously is $1 \times 10^{-3}$, in addition, it is shown that the failure location of 
immersed tube locates outside the top plate in the channel, it is only required to analyze the failure of immersed tube through contrasting the shearing strain increment diagram outside the top plate in the channel of immersed tube while different reduction factors.
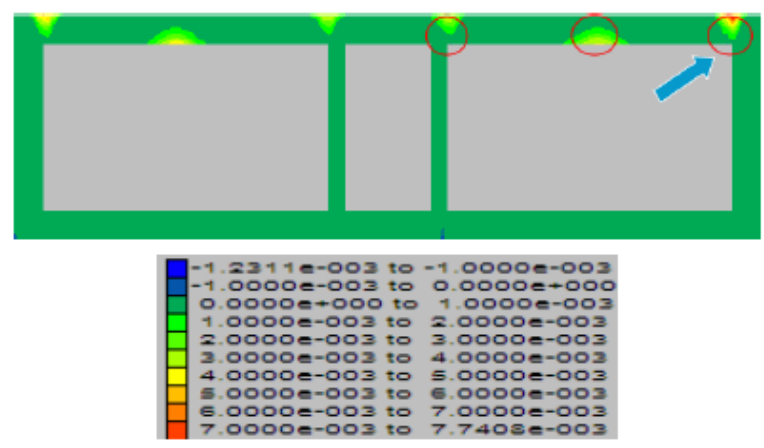

(a)Shearing strain increment of immersed tube
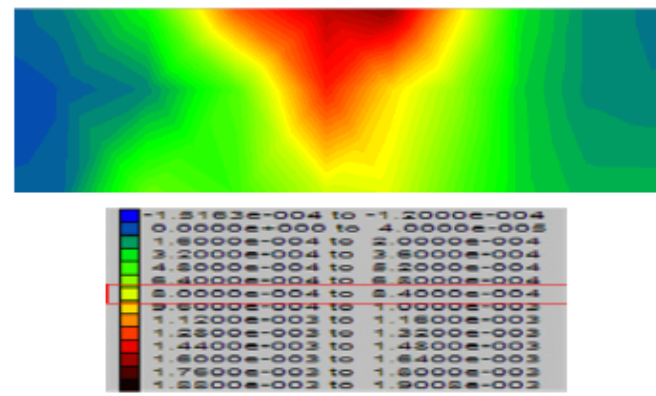

(b) Shearing strain increment outside the top plate in the channel

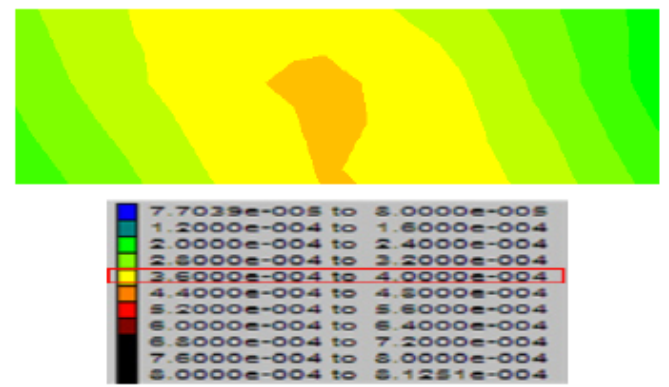

(c) Shearing strain increment in the top plate in the channel
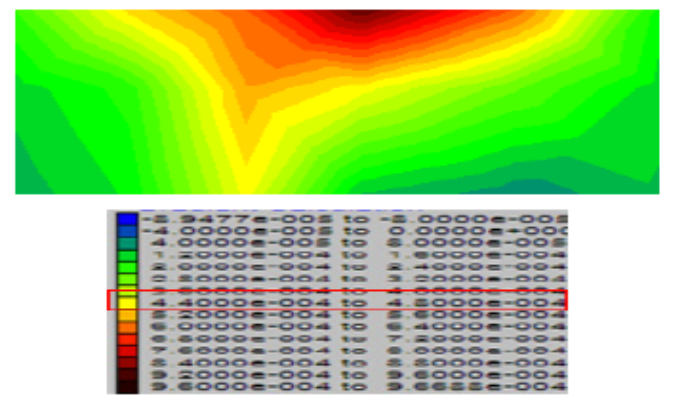

(d) Shearing strain increment inside the top plate in the channel

Fig. (7). Comparison on shearing strain increment for immersed tube.

When the strength reduction factor is $2.05,2.08$ and 2.1 respectively, the shearing strain increment outside the top plate in the immersed tube channel is as shown in Fig. (8). When the reduction factor is 2.05 , the minimum of shearing strain is $0.85 \times 10^{-3}$ not to reach the limit shearing increment $1 \times 10^{-3}$; When the reduction factor is 2.08 , the minimum of shearing strain $1.0 \times 10^{-3}$ to reach the limit shearing increment $1 \times 10^{-3}$, showing that the immersed tube fails outside the top plate in the channel at this moment; when the reduction factor is 2.1 , the minimum of shearing strain is $1.1 \times 10^{-3}$ to exceed the limit shearing strain increment $1 \times 10^{-3}$, showing that the immersed tube has already been destroyed.

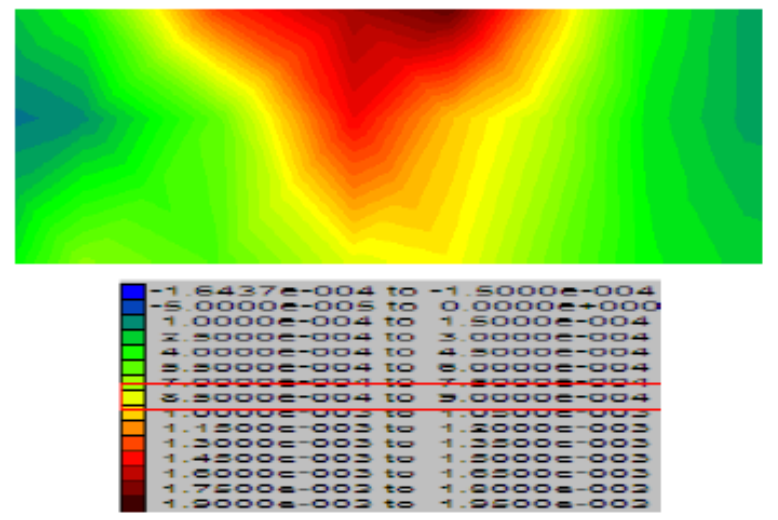

(a) reduction factor 2.03
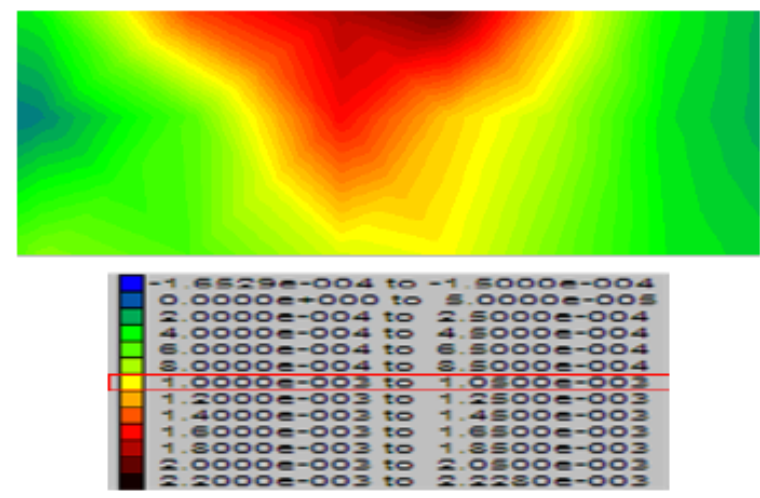

(b) reduction factor 2.08
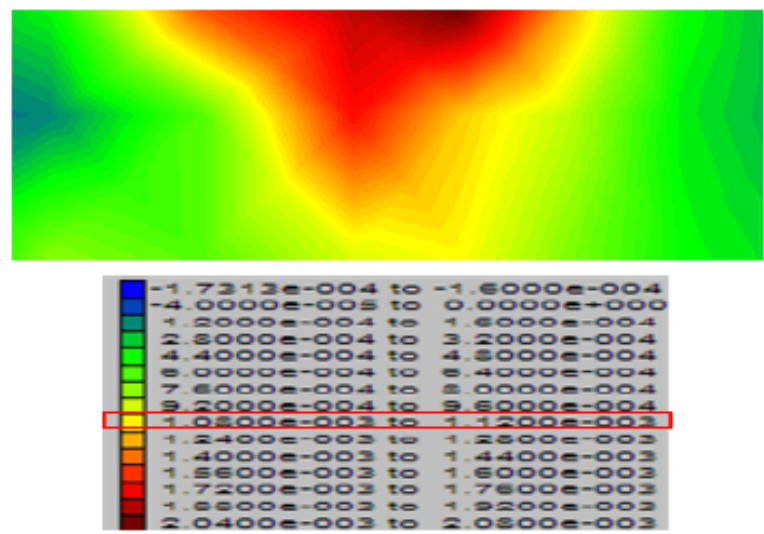

(c) reduction factor 2.1

Fig. (8). Comparison for shearing strain increment outside top plate of immersed tube.

Therefore, when the thickness of sludge on the top plate in the subsea reinforced concrete immersed tube tunnel is $3 \mathrm{~m}$, the water depth is $10 \mathrm{~m}$ and the wavelength of functioning seismic wave is $10 \mathrm{~s}$ as well as the peak acceleration is 
$0.2 \mathrm{~g}$, the safety factor takes 2.08 , and the failure location is outside the top plate in the immerses tube channel, the failure surface of top plate for immersed tube is as shown in Fig. (9) at this moment.

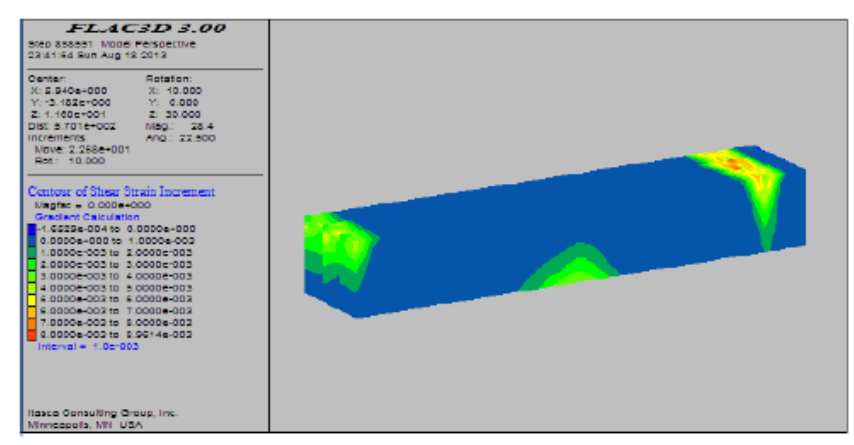

Fig. (9). Failure surface of numerical simulation top plate for immersed tube.

\subsection{Whole Process of Immersed Tube Failure}

Previously, the limit shearing strain increment method is applied to judge the instability failure when the fissure of immersed tube cuts through. However, the failure of immersed tube isn't brittle, but there is certain development process. In combination with the curve that the sinking displacement of top plate changes along with strength reduction factor, the whole failure process of immersed tube may be analyzed.

\subsubsection{Relation between sinking displacement and strength reduction factor for top plate of immersed tube}

Under dead weight loading function of immersed tube, soil mass and seawater, after the seismic wave is imposed for 10 s, the corresponding sinking displacement in the middle of top plate in the main channel of immersed tube under different strength reduction factors for immersed tube is as shown in Table 3. It is required to be explained that the sinking displacement in the middle of top plate is selected for sinking displacement. While analyzing the failure, since it has been described previously that the easily-destroyed location for immersed tube locates outside the top of immersed tube, therefore, the outside of top tube is selected to analyze the failure of immersed tube.

Relation curve between relative sinking displacement and strength reduction factor is as shown in Fig. (10).

\subsubsection{Elasticity Stage}

As shown in Fig. (10), when the reduction factor is $1.0 \sim 1.6$, the relation between top plate displacement and reduction factor presents the straight-line distribution to show that the immersed tube is on elasticity stage. During elasticity stage, the shearing strain of immersed tube is tiny, and the immersed tube doesn't crack.

\subsubsection{Plasticity Stage}

As shown in Fig. (10), when the reduction factor is greater than 1.6, the relation between top plate displacement and reduction factor presents the curve distribution to show that the immersed tube begins to be on plasticity stage.

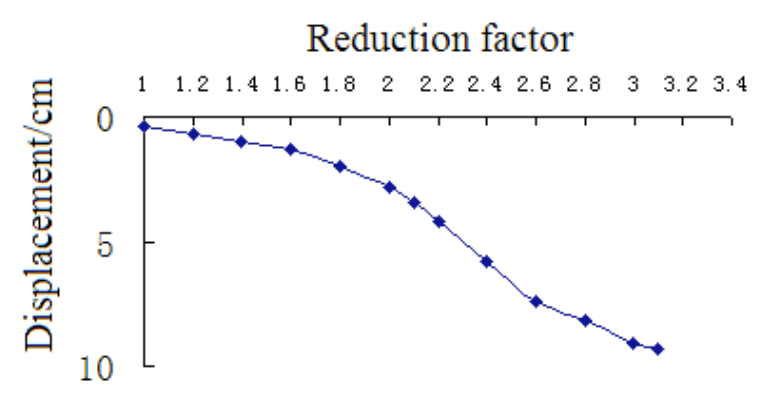

Fig. (10). Relation curve between relative sinking displacement and strength reduction factor

\subsubsection{Fissure Commencement Stage}

During plasticity stage, the shearing strain of immersed tube increases gradually along with increase of reduction factor. When the reduction factor reaches 2.0, the maximal shearing strain outside the top plate of immersed tube is $7.7 \times 10^{-3}$ to be greater than the limit shearing strain $1 \times 10^{-3}$, showing that the fissure begins here, as shown in Fig. (11).

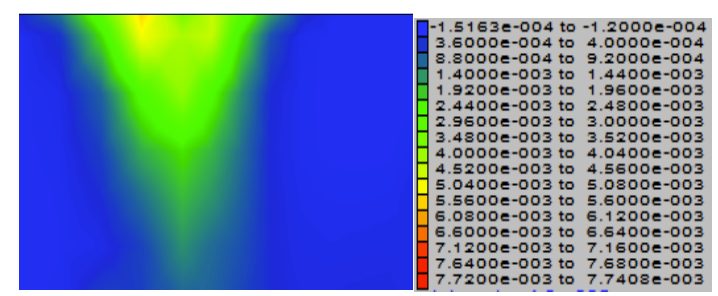

Fig. (11). Strain increment outside top plate when the reduction factor is 2.0 .

\subsubsection{Fissure Cutthrough Stage}

The reduction factor continuously increases. When the reduction factor reaches 2.6 , the minimal shearing strain outside the top plate of immersed tube is $2.1 \times 10^{-3}$, as shown in Fig. (12). At this moment, the shearing strain increment of this cross section outside the top plate of immersed tube is greater than the limit shearing strain increment $1 \times 10^{-3}$, therefore, the fissure outside the top plate of immersed tube cuts

Table 3. Strength reduction factor and settlement of top plate $(\mathrm{cm})$.

\begin{tabular}{|l|l|l|l|l|l|l|}
\hline Reduction factor & 1 & 1.2 & 1.4 & 1.6 & 1.8 & 2 \\
\hline Displacement & 0.4 & 0.7 & 1 & 1.3 & 2 & 2.8 \\
\hline Reduction factor & 2.2 & 2.4 & 2.6 & 2.8 & 3 & 3.1 \\
\hline Displacement & 4.2 & 5.8 & 7.4 & 8.2 & 9.1 & 9.3 \\
\hline
\end{tabular}


through. It is deemed generally that, if the structural fissure of immersed tube cuts through, it is deemed that the instability failure has been produced.

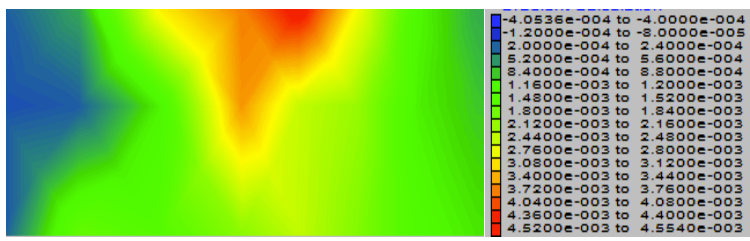

Fig. (12). schematic diagram for minimum of strain increment outside top plate when the reduction factor is 2.6 .

\subsubsection{Collapse Stage of Immersed Tube}

The reduction factor continuously increases. When the reduction factor is 3.1 , the sinking displacement of top plate for immersed tube is $9.3 \mathrm{~cm}$, and when continuously increases up to 3.2 , the sinking displacement of top plate for immersed tube changes as infinity suddenly, at this moment, the computation result of FLAC software hasn't been converged yet, showing that the immersed tube produces the collapse failure.

\subsection{Comparison for Different Seismic Waves Under Function of Immersed Tunnel}

The immersed tunnel bears the seismic wave function. The duration of wave is different, the peak acceleration is different, and there is difference for stability analysis of structure possibly. In order to reflect this kind of difference, four groups of seismic wave are selected, respectively referring to: duration of (1) wave is $7 \mathrm{~s}$, the peak acceleration is $0.2 \mathrm{~g}$,Wave A for short; duration of (2) wave is $10 \mathrm{~s}$, the peak acceleration is $0.2 \mathrm{~g}$, Wave B for short; duration of (3) wave is $10 \mathrm{~s}$, the peak acceleration is $0.22 \mathrm{~g}$, Wave $\mathrm{C}$ for short; duration of (4) wave is $7 \mathrm{~s}$, the peak acceleration is $0.2 \mathrm{~g}$, Wave D for short. The time travel curve graph of wave peak acceleration is as shown in Fig. (3).

\subsubsection{Comparison for Failure Location of Immersed Tube}

The immersed tunnel is functioned by four kinds of A, B, $\mathrm{C}$ and $\mathrm{D}$ seismic wave respectively. When the reduction factor is 2.0 and the simulation ends, the minimum of shearing strain increment inside the top plate, outside the top plate and in the top plate for immersed tube is as shown in Table 4. It may be observed from Table 4 that, the seismic wave functioned by immersed tube is different, the shearing strain increment is different, however, the shearing strain increment outside the top plate is maximal always, the limit shearing strain increment of immersed tube may reach firstly and exceed as well as produce the failure here. Therefore, different seismic waves functioned by the immersed tube, the failure location locates outside the top plate in the immersed tube channel.

\subsubsection{Comparison for Safety Factor of Immersed Tube}

The reinforced concrete immersed tube at the seabed undertakes the function by seismic wave. When the minimal shearing strain increment outside the top plate in the immersed tube channel exceeds the limit shearing strain increment, we deem that the immersed tube is destroyed and the reduction factor is defined as safety factor. For this reinforced concrete immersed tube, four kinds of A, B, C and D seismic wave are functioned respectively. When the minimal strain increment outside the top plate in the channel reaches the limit shearing strain increment $1 \times 10^{-3}$, the reduction factor is $2.18,2.08,2.0$ and 2.45 respectively; the corresponding shearing strain increment outside the top plate of immersed tube is as shown in Fig. (13).

The reinforced concrete immersed tunnel at seabed respectively functions four kinds of $\mathrm{A}, \mathrm{B}, \mathrm{C}$ and $\mathrm{D}$ wave. After the simulation ends, the safety factor of immersed tube is as shown in Table 5. Through contrasting and comparison between Table 5 and Fig. (3), following disciplines may be obtained: (1) The time travel curve of acceleration has great

Table 4. Comparison for shearing strain increment at different locations.

\begin{tabular}{|c|c|c|c|}
\hline Seismic wave & Inside top plate & In the top plate & Outside top plate \\
\hline \hline A & $0.32 \times 10^{-3}$ & $0.25 \times 10^{-3}$ & $0.36 \times 10^{-3}$ \\
\hline B & $0.45 \times 10^{-3}$ & $0.4 \times 10^{-3}$ & $0.8 \times 10^{-3}$ \\
\hline C & $0.65 \times 10^{-3}$ & $0.4 \times 10^{-3}$ & $0.75 \times 10^{-3}$ \\
\hline D & $0.15 \times 10^{-3}$ & $0.15 \times 10^{-3}$ & $0.38 \times 10^{-3}$ \\
\hline
\end{tabular}

Table 5. Comparison for safety factor for functioned different waveforms.

\begin{tabular}{|c|c|c|c|c|}
\hline Seismic wave & Duration & Peak acceleration & Safety Coefficient & $\begin{array}{c}\text { Time Travel Curve Diagram } \\
\text { for Acceleration }\end{array}$ \\
\hline \hline A & $7 \mathrm{~s}$ & $0.2 \mathrm{~g}$ & 2.18 & Similar \\
\hline $\mathrm{B}$ & $10 \mathrm{~s}$ & $0.2 \mathrm{~g}$ & 2.08 & Similar \\
\hline $\mathrm{C}$ & $10 \mathrm{~s}$ & $0.22 \mathrm{~g}$ & 2.0 & Similar \\
\hline $\mathrm{D}$ & $7 \mathrm{~s}$ & $0.2 \mathrm{~g}$ & 2.45 & Different \\
\hline
\end{tabular}


influence on safety factor of immersed tube, the curve shape is different, the difference of safety factor is great. Especially, the later the peak acceleration, the lower the safety factor of immersed tube and more dangerous; (2) The duration of seismic wave has greater on safety factor of immersed tube; (3) The peak acceleration of seismic wave has greater influence on safety factor of immersed tube, the greater the peak acceleration, the lower the safety factor of immersed tube and more dangerous.

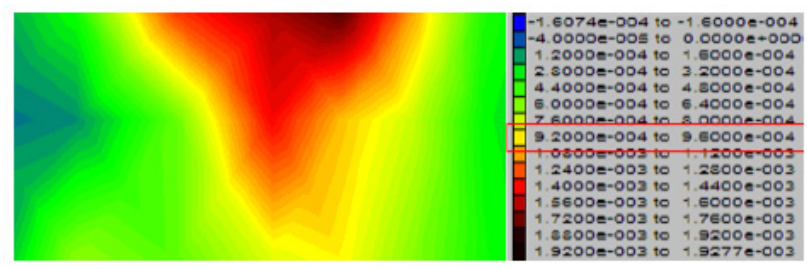

(a)Wave A safety factor 2.18

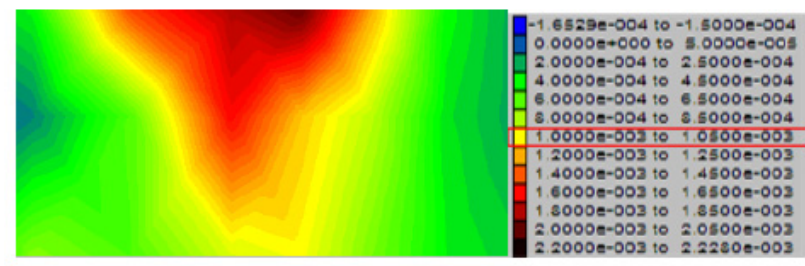

(b) Wave $\mathrm{B}$ reduction factor 2.08

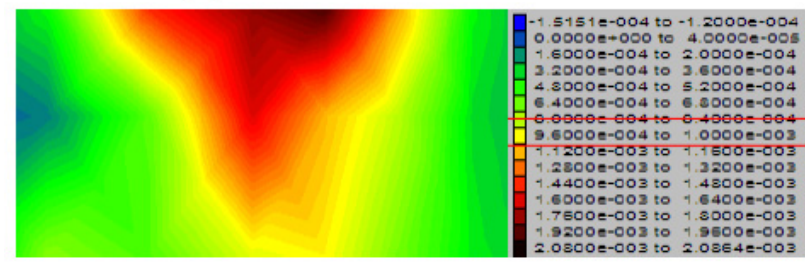

(c) Wave $\mathrm{C}$ reduction factor 2.0

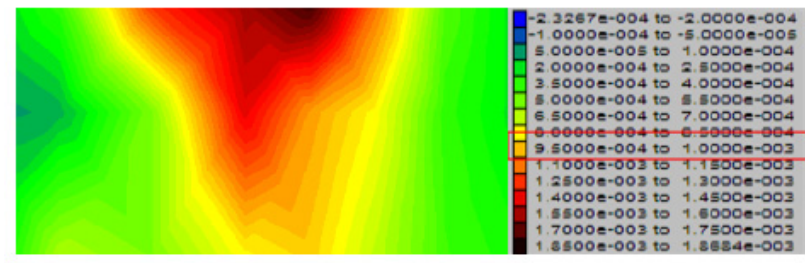

(d) Wave D reduction factor 2.45

Fig. (13). Shearing strain increment outside top plate in the immersed tube channel.

\section{CONCLUSION}

The strength reduction method is adopted to discuss the safety stability of reinforced concrete immersed tube under the function of seismic force in this paper, following conclusions may be obtained:

(1) Through numerical simulation analysis, the authors put forward the judgment criterion on dynamic unstability failure for reinforced concrete immersed tunnel at seabed: when the shearing strain increment of each point on certain cross section for reinforced concrete immersed tube is greater than the shearing strain increment under limit equilibrium state uniformly, the immersed tube produces the unstability failure, right now, the reduction factor is defined as the safe- ty factor of immersed tube, and the examples are given to explain the specific computation method of safety factor for immersed tube.

(2) Under the function that the reinforced concrete immersed tunnel at seabed undertakes the function of earthquake force, the shearing strain increment outside the top plate in the immersed tube channel is maximal, while the failure of immersed tube occurs here generally.

(3) In combination with variation curve that the limit shearing strain increment method and sinking displacement of top plate change along with strength reduction factor, the whole failure process of immersed tube is analyzed.

(4) The failure for reinforced concrete immersed tunnel at seabed under different function by different seismic waves is compared to obtain the influence discipline on safety factor of immersed tube by time travel curve of acceleration, duration of seismic wave and peak acceleration of seismic wave.

It is a try that the strain failure mechanism of concrete equivalent materials is applied into stability analysis of earthquake for reinforced concrete immersed tunnel at seabed, the purpose is to discuss a more reasonable method to judge the instability of reinforced concrete immersed tunnel and get the more rational safety factor.

\section{CONFLICT OF INTEREST}

The authors confirm that this article content has no conflict of interest.

\section{ACKNOWLEDGEMENTS}

This work is supported by the national key research and development program (973) project (2011CB013600, 2011CB710603); National Natural Science Foundation of China (NSFC) (51378496); Chongqing Natural Science Foundation for Academician of special Project (CSTC2013jcyjys0002).

\section{REFERENCES}

[1] P.R. Taylor, H.H. Ibrahim and D. Yang, "Seismic retrofit of George Massey tunnel", Earthquake Engineering an Strural Dynamics, vol. 34, no. 4/5, pp. 519-42, 2005.

[2] I. Anastasopoulos, N. Gerolymos, V. Drosos and T. Georgarakos, "Nonlinear response of deep immersed tunnel to strong seismic shaking", Journal of Geotechnical and Geoenvironmental Engineering, vol. 13, no. 39, pp. 1067-1090, 2007.

[3] H. Yang and J. Lu, "Vibration analysis of a subaqueous tunnel of huangpu river during earthquake, Joural of shang hai Jiao tong University, vol. 35, no. 10, pp. 1512-1516, 2001.

[4] Y. Zheng and S. Zhao, "Limit state finite element methord for geotechnical engineering analysis and its application" Chinese Civil Engineering Journal, vol. 38, no. 1, pp. 91-104, 2005.

[5] Y. Zheng and S. Zhao, A. Li, "FEM limit analysis and its application in slope engineering", Beijing: China Communications Press, pp. 181-199, 2011.

[6] B. Liu and Y. Han, FLAC theory, examples and application guide, Beijing: China Communications Press 2005.

[7] X. Kou, W. Zhou and R. Yang. "FLAC3D analysis of high slope of Three Gorges shiplock stability", Chinese Journal of Rock Mechanics and Engineering 2001, vol. 20, no. 1, pp. 6-10. 
[8] Y. Zheng, S. Zhao and A. Li, "FEM limit analysis and its application in slope engineering", Beijing: China Communications Press, pp. 181-199, 2011.

[9] Y. Zheng, H. Ye R. Huang, "Analysis and discussion of failure mechanism and fracture surface of slope under earthquake", Chi- nese Journal of Rock Mechanics and Engineering vol. 28, no. 8, ppl. 1714-1723, 2009.

[10] Y. Zheng, H. Ye R. Huang, "Study on the seismic stability analysis of a slope" Journal of Earthquake Engineering and Engineering, vol. 30 , no. 2 , pp. $66-73,2010$

Received: May 26, 2015

Revised: July 14, 2015

Accepted: August 10,2015

(C) Bo et al.; Licensee Bentham Open.

This is an open access article licensed under the terms of the (https://creativecommons.org/licenses/by/4.0/legalcode), which permits unrestricted, noncommercial use, distribution and reproduction in any medium, provided the work is properly cited. 